\title{
Evaluation of cloud effects on air temperature estimation using MODIS LST based on ground measurements over the Tibetan Plateau
}

\author{
Hongbo Zhang ${ }^{1,2}$, Fan Zhang ${ }^{1,2}$, Guoqing Zhang ${ }^{1,2}$, Xiaobo He $^{3}$, and Lide Tian ${ }^{1,2}$ \\ ${ }^{1}$ Key Laboratory of Tibetan Environment Changes and Land Surface Processes, Institute of Tibetan Plateau Research, \\ Chinese Academy of Sciences, Beijing, China \\ ${ }^{2}$ CAS Center for Excellence in Tibetan Plateau Earth Sciences, Beijing, China \\ ${ }^{3}$ Cold and Arid Regions Environmental and Engineering Research Institute, Chinese Academy of Sciences, Lanzhou, China
}

Correspondence to: Hongbo Zhang (zhanghongbo@itpcas.ac.cn)

Received: 18 August 2016 - Published in Atmos. Chem. Phys. Discuss.: 23 August 2016

Revised: 21 October 2016 - Accepted: 24 October 2016 - Published: 4 November 2016

\begin{abstract}
Moderate Resolution Imaging Spectroradiometer (MODIS) daytime and nighttime land surface temperature (LST) data are often used as proxies for estimating daily maximum $\left(T_{\max }\right)$ and minimum $\left(T_{\min }\right)$ air temperatures, especially for remote mountainous areas due to the sparseness of ground measurements. However, the Tibetan Plateau (TP) has a high daily cloud cover fraction (>45\%), which may affect the air temperature ( $\left.T_{\text {air }}\right)$ estimation accuracy. This study comprehensively analyzes the effects of clouds on $T_{\text {air }}$ estimation based on MODIS LST using detailed halfhourly ground measurements and daily meteorological station observations collected from the TP. It is shown that erroneous rates of MODIS nighttime cloud detection are obviously higher than those achieved in daytime. Large errors in MODIS nighttime LST data were found to be introduced by undetected clouds and thus reduce the $T_{\min }$ estimation accuracy. However, for $T_{\max }$ estimation, clouds are mainly found to reduce the estimation accuracy by affecting the essential relationship between $T_{\max }$ and daytime LST. The errors of $T_{\max }$ estimation are obviously larger than those of $T_{\min }$ and could be attributed to larger MODIS daytime LST errors that result from higher degrees of LST heterogeneity within MODIS pixel compared to those of nighttime LST. Constraining MODIS observations to non-cloudy observations can efficiently screen data samples for accurate $T_{\min }$ estimation using MODIS nighttime LST. As a result, the present study reveals the effects of clouds on $T_{\max }$ and $T_{\min }$ estimation through MODIS daytime and nighttime LST, respectively, so as to help improve the $T_{\text {air }}$ estimation accuracy
\end{abstract}

and alleviate the severe air temperature data sparseness issues over the TP.

\section{Introduction}

Air temperature is a key variable used to describe environmental conditions. However, temperature observations are typically sparse in remote mountainous areas (Lin et al., 2016). Remotely sensed land surface temperatures (LST) can serve as an efficient proxy for air temperature estimation in such areas. Superior to limited ground measurements, remote sensing can provide more spatiotemporal information. Several studies have estimated air temperatures using Moderate Resolution Imaging Spectroradiometer (MODIS) land surface temperature products for Europe (Benali et al., 2012; Kilibarda et al., 2014), Canada (Xu et al., 2014), USA (Oyler et al., 2015; Parmentier et al., 2015; Oyler et al., 2016), Africa (Vancutsem et al., 2010; Lin et al., 2012), western Asia (Emamifar et al., 2013) and the Tibetan Plateau (TP) (Fu et al., 2011; Zhu et al., 2013).

Due to its high altitudes, the TP and surrounding areas include the largest cryosphere area outside the Arctic and Antarctic regions and Greenland, and it is considered to be among the areas that are most sensitive to climate change. However, most meteorological stations in the TP are located in low-altitude $(<4800 \mathrm{~m})$ and eastern regions (Fig. 1). There are almost no stations in the vast western area or at the elevations above $5000 \mathrm{~m}$. In particular, for glacier covered ar- 


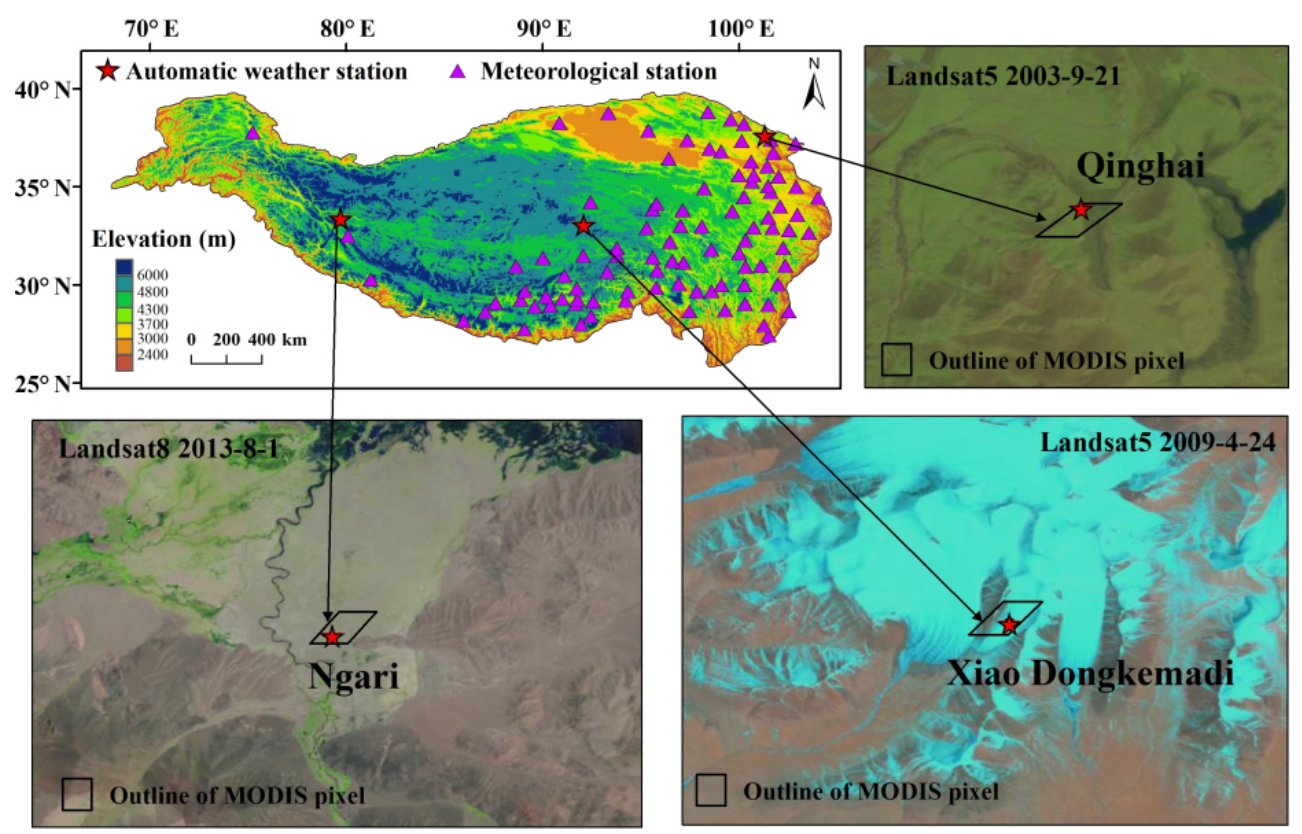

Figure 1. Map of the TP marking AWS and meteorological station locations. Landsat images observed during the time period for data used in this study are also shown in natural color modes with acquired dates. The outline of the MODIS grid is also plotted.

eas temperature observations are extremely scarce (Wu et al., 2015). Remotely sensed LSTs can help greatly alleviate the problems associated with scarce temperature observations available for the TP.

Despite the advantages of high spatial and temporal accessibility to large-scale areas, remote sensing data present some limitations, among which cloud contamination issues may be the most important. For applications of MODIS LST, clouds can affect the $T_{\text {air }}$ (air temperature) estimation in at least two ways: erroneous cloud identification can reduce the accuracy of MODIS LST values, and the presence of clouds can affect the relationship between LST and $T_{\text {air }}$ and can further affect the accuracy of $T_{\text {air }}$ estimations.

The presence of clouds can greatly decrease the amount of data available in the satellite images. Moreover, the existing cloud detection algorithms cannot identify all the cloudy pixels, and a considerable percentage of undetected cloudy pixels exists in MODIS LST products (reported at roughly $15 \%$ ) (Ackerman et al., 2008). It has been shown through some validation studies that extremely large differences $(>10 \mathrm{~K})$ between MODIS LST and ground measurements occasionally occur, even for homogeneous surfaces. In these cases, the cloud top temperatures can be taken as the LST values (Langer et al., 2010; Westermann et al., 2011). More recently, up to $40 \%$ of ground-measured cloudy samples have been labeled unidentified according to field observations, thus producing rather large MODIS LST errors, as reported for Svalbard (Østby et al., 2014). Such errors can disturb the true relationship between LST and air temperatures $\left(T_{\text {air }}\right)$. MODIS daytime LST has been found to be affected by unidentified cloudy pixels, causing such pixels to severely degrade LST$T_{\text {air }}$ relationships (Williamson et al., 2013). Because the daytime cloud algorithm is expected to present more confidence than that for nighttime (Ackerman et al., 1998), using the nighttime LST for air temperature estimation may be influenced more by undetected clouds. For the TP, cloud contamination also constitutes a major problem, generating a mean daily cloud cover fraction of $>45 \%$ (Yu et al., 2016). Thus, the effects of clouds are particularly essential for $T_{\text {air }}$ estimation in the TP.

In addition to the effects of undetected cloudy pixels, clouds are expected to play a key role in the relationship between LST and $T_{\text {air }}$ due to its cooling effects during the day and warming effects at night (Dai et al., 1999). During the day, clouds can decrease land surface warming rates by blocking solar radiation, and at night clouds can reflect surface long-wave radiation and decrease heat losses from the land surface producing higher ground temperatures than those detected on clear days. For example, the difference between observed daytime LST and $T_{\text {air }}$ under cloudy conditions is much lower (an average of $\sim 3.7^{\circ} \mathrm{C}$ ) than that observed under clear conditions (Gallo et al., 2011). Therefore, questions regarding whether and how clouds can affect $T_{\max }-$ daytime LST and $T_{\min }$-nighttime LST relationships have been posed. Previous $T_{\text {air }}$ estimations based on MODIS LST are presumably valid for clear conditions (Shen and Leptoukh, 2011; Oyler et al., 2015). However, satellite-observed LSTs (at night or during the day) are instantaneous and may have a time lag between the overpass time and the time when $T_{\text {air }}$ reaches its minimum or maximum. Daily cloudiness con- 
ditions may affect the warming (during the day) or cooling (at night) rates and can further alter the relationship between $T_{\text {air }}$ and LST.

Previous studies have mainly focused on two types of daily $T_{\text {air }}$ estimations: daily maximum $\left(T_{\max }\right)$ and minimum $\left(T_{\min }\right)$ air temperatures (Benali et al., 2012; Xu et al., 2014; Good, 2015). In addition, daytime and nighttime LST have been used as predictors for $T_{\max }$ and $T_{\min }$ estimations, respectively, due to their different overpass times (Vancutsem et al., 2010; Lin et al., 2012; Oyler et al., 2016). Recent studies have interestingly found that the estimation accuracy of $T_{\max }$ based on daytime LST is clearly lower than that of $T_{\min }$ based on nighttime LST (Zhang et al., 2011; Benali et al., 2012; Oyler et al., 2016), and nighttime LST has an even higher correlation with $T_{\max }$ than daytime LST (Zhang et al., 2011; Zeng et al., 2015). Benali et al. (2012) hypothesized that the presence of cloud cover may decrease daytime warming levels, resulting in incorrect modeling and negative effects of cloud cover on estimation accuracies. Oyler et al. (2016) instead attributed this to the large microscale variability differences between daytime and nighttime LST.

Due to the scarcity of detailed cloud observations available, few studies have focused on the potentially important effects of clouds on estimations of $T_{\text {air }}$ that use remotely sensed LST. This study explores the effects of clouds on $T_{\text {air }}$ estimation using MODIS LST based on detailed halfhourly ground measurements and the daily China Meteorological Administration (CMA) station observations. For the TP, sufficiently detailed observations are extremely rare and related studies have not been conducted before. Three automatic weather stations (AWS) with half-hourly-averaged observations are examined in this study, including one valuable site positioned on a glacier. To make our study more representative, data drawn from 92 CMA stations that include daily $T_{\max }$ and $T_{\min }$ observations are also used for cloud effect tests.

\section{Data}

\subsection{Ground measurements}

In this study, detailed observations from three AWSs on the TP were obtained (Fig. 1). The Ngari station is located in the western area of the TP at an elevation of $4270 \mathrm{~m}$. Desert grassland constitutes the main form of land cover here. The Qinghai station is located in the northeastern TP at an elevation of $3250 \mathrm{~m}$ and is dominated by alpine meadow. The Xiao Dongkemadi station is located in the interior TP at an elevation of $5621 \mathrm{~m}$ on the Xiao Dongkemadi glacier (Fig. 1). The general features of the three AWSs are listed in Table 1. In addition, daily $T_{\max }$ and $T_{\min }$ observations measured at $2 \mathrm{~m}$ above the ground surface from 92 CMA stations over the TP are also used for assistant analysis. Data drawn from these CMA stations are from 2007 to 2010.
All three AWSs provide half-hourly-averaged ingoing and outgoing long-wave radiation, and air temperature data. Through controlling the data quality, obvious outliers have been removed for all three AWSs. These radiation data were measured using a widely used CNR1 net radiometer at an uncertainty level of $\pm 10 \%$ for daily totals set by the manufacturer. Air temperatures were collected using an HMP45C sensor with expected accuracies of $\pm 0.2-0.5^{\circ} \mathrm{C}$ depending on the temperature ranges involved. Detailed measurement specifications are listed in Table 1. However, only the Xiao Dongkemadi station provides the directly measured LST values, which were obtained through an Apogee Precision Infrared Thermocouple Sensor (IRTS-P) with an accuracy of $0.3 \mathrm{~K}$ over the glacier surface (Huintjes et al., 2015). The LSTs of the Qinghai and Ngari stations were derived based on the Stefan-Boltzmann law and the thermal radiative transfer theory:

$L_{\mathrm{u}}=\sigma T_{\mathrm{b}}^{4}=(1-\varepsilon) L_{\mathrm{d}}+\varepsilon \sigma T_{\mathrm{s}}^{4}$,

where $L_{\mathrm{u}}$ and $L_{\mathrm{d}}$ are the upwelling and downwelling longwave radiation, respectively, $\sigma$ is the Stefan-Boltzmann constant $\left(5.670367 \times 10^{-8} \mathrm{~W} \mathrm{~m}^{-2} \mathrm{~K}^{-4}\right), \varepsilon$ is land surface emissivity, $T_{\mathrm{b}}$ is the brightness temperature, and $T_{\mathrm{s}}$ is the land surface temperature. The calculated LSTs were taken as ground measurements of LST as Wang et al. (2008).

In this study, emissivity values were assigned empirically due to a lack of measurements. Emissivity values for the Qinghai and Ngari stations were set to 0.987 (alpine meadow) and 0.975 (desert grassland), respectively, according to Wang et al. (2008). To partly quantify the effects of emissivity value uncertainty, simple sensitivity tests were conducted. A 0.001 change in emissivity is on average found to result in the LST change of 0.015 and $0.020 \mathrm{~K}$ for stations Qinghai and Ngari, respectively.

\subsection{MODIS land surface temperatures}

Daily 1-km LST products of MODIS level 3 collection 5 are used in this study including the data from the Terra (MOD11A1) and Aqua (MYD11A1) satellites. Both Terra and Aqua generate two daily observations, including one for daytime and one for nighttime. The two overpass times for Aqua are approximately 01:30 and 13:30 local time (LT). For Terra, these times are approximately 10:30 and 22:30 LT. Accurate view times can be derived from the product. The MODIS LST used here is retrieved using the generalized split-window algorithm (Wan and Dozier, 1996). Accuracies are reported to range within $1 \mathrm{~K}$, but the uncertainties and errors of emissivity used in the MODIS LST product can be significant, which produces major errors (Wan et al., 2002). Each grid of the MODIS LST product includes a quality control (QC) flag that ranges from 0 to 3 indicating the average errors of $<1,1-2,2-3$, and $>3 \mathrm{~K}$. Records with a QC flag of 3 were omitted in this study. 
Table 1. Summary of the AWS sites.

\begin{tabular}{lrrrrrr}
\hline AWS & Long/Lat & $\begin{array}{r}\text { Mean annual } \\
\text { precipitation } \\
(\mathrm{mm})\end{array}$ & $\begin{array}{r}\text { Mean annual air } \\
\text { temperature } \\
\left({ }^{\circ} \mathrm{C}\right)\end{array}$ & $\begin{array}{r}\text { Elevation } \\
(\mathrm{m})\end{array}$ & Land cover & Time period \\
\hline Xiao Dongkemadi & $92.08 / 33.07$ & 680 & -8.6 & 5621 & Glacier & Jan 2009-Dec 2009 \\
Ngari & $79.70 / 33.39$ & 125 & 1.2 & 4270 & Desert grassland & Jun 2012-Dec 2013 \\
Qinghai & $101.30 / 37.60$ & 567 & -1.7 & 3250 & Alpine meadow & Jan 2003-Dec 2004 \\
\hline
\end{tabular}

The MODIS observations are instantaneous, whereas the ground measurements used are half-hourly averaged. To make them comparable, the timing of ground observations recorded on Beijing time was converted to local solar time. Then, half-hourly observations that were within 15 min of the view times of MODIS record times were selected.

\section{Methods}

The procedure for analyzing cloud effects step by step are outlined in Fig. 2, and described in detail as follows.

\subsection{Cloud index estimations}

Cloud observations are usually only available from nonautomatic weather stations and are difficult to record. In this study, an efficient method was employed to estimate cloudiness based on downwelling long-wave radiation $\left(L_{\mathrm{d}}\right)$ records and air temperatures, which have been widely used in other studies (Giesen et al., 2008; Yang et al., 2011; Østby et al., 2014). This theory is mainly based on the principle that under cloudy conditions, a long-wave radiation balance exists between cloud base and near surface (Giesen et al., 2008; Østby et al., 2014). Under overcast conditions, both the cloud base and the near surface radiate at similar temperatures and $L_{\mathrm{d}}$ reaches its maximum. However, $L_{\mathrm{d}}$ should be much lower under clear conditions than under overcast conditions under the same temperature. In such a case, $L_{\mathrm{d}}$ reaches its minimum. Thus, a maximum $L_{\mathrm{d}}$ can be reversed using the Stefan-Boltzmann law under a given air temperature, and the minimum $L_{\mathrm{d}}$ can be regressed using the polynomial fit of the lower 5th percentile of the $L_{\mathrm{d}}$ observations for each specified temperature interval (1 K here) (Østby et al., 2014). When $L_{\mathrm{d}}$ is assumed to linearly increase from clear to overcast conditions at a given temperature, then a "cloud index" (CI) indicating the cloudiness can be achieved $(\mathrm{CI}=0$ and 1 for clear and overcast skies, respectively) (Giesen et al., 2008; Yang et al., 2011; Østby et al., 2014). For example, for an observed downwelling long-wave radiation where $L_{i}$ is at the temperature $T_{i}$, if the $L_{\max }$ and $L_{\min }$ are the maximum and minimum $L_{\mathrm{d}}$ under that temperature $\left(T_{i}\right)$, respectively, then the $\mathrm{CI}$ is determined as $\left(L_{i}-L_{\min }\right) /\left(L_{\max }-L_{\min }\right)$. Rather than the visually observed percentage of cloud cover in the sky, the
CI used here represents the optical thickness of clouds (Van Den Broeke et al., 2006).

\subsection{Testing cloud effects on the accuracies of MODIS LST}

Undetected clouds may exist in the MODIS LST data as a result of erroneous cloud identification. An evaluation of the number of undetected clouds present was conducted first. As considerable errors can be introduced by undetected clouds, the effects of clouds on MODIS LST accuracies were evaluated by comparing validation (MODIS vs. observed LST) results derived before and after removing the undetected cloudy records. In this study, the records with $\mathrm{CI}>0.5$ are considered to be under "mostly cloudy" conditions. For a given MODIS observation, it is regarded as an undetected cloud if its corresponding $\mathrm{CI}>0.5$.

In this study, all four MODIS observations derived from the Terra and Aqua satellites were validated to identify and explain the effects of clouds on $T_{\text {air }}$ estimations. It should be noted that the effects of undetected clouds may come from or be mixed with the effects of residual/thin clouds (Platnick et al., 2003), fogs (Østby et al., 2014) and some thick aerosol layers (Huang et al., 2014) existing in the MODIS pixel, which may impose errors on the MODIS LST product to varying degrees. Even though these effects are hard to distinguish in detail, undetected clouds are generally considered to have strong negative effects on the accuracies of MODIS LST (Williamson et al., 2013; Østby et al., 2014; Shamir and Georgakakos, 2014).

\section{3 $T_{\text {air }}$ estimation}

Various statistical methods have been used for $T_{\text {air }}$ estimation using MODIS LST, including neural network (Jang et al., 2004), random forests (Xu et al., 2014), M5 model tree (Emamifar et al., 2013), and the simple linear regression (Zhang et al., 2011; Benali et al., 2012; Lin et al., 2012). Comparisons among the performances of six types of statistical models with different levels of complexity for $T_{\text {air }}$ estimation indicate that though there truly exist some cases where advanced statistical models clearly outperform the simple linear regression model, the absolute differences of accuracies produced by different models are generally not big, especially for cases using MODIS nighttime LST (Zhang et 


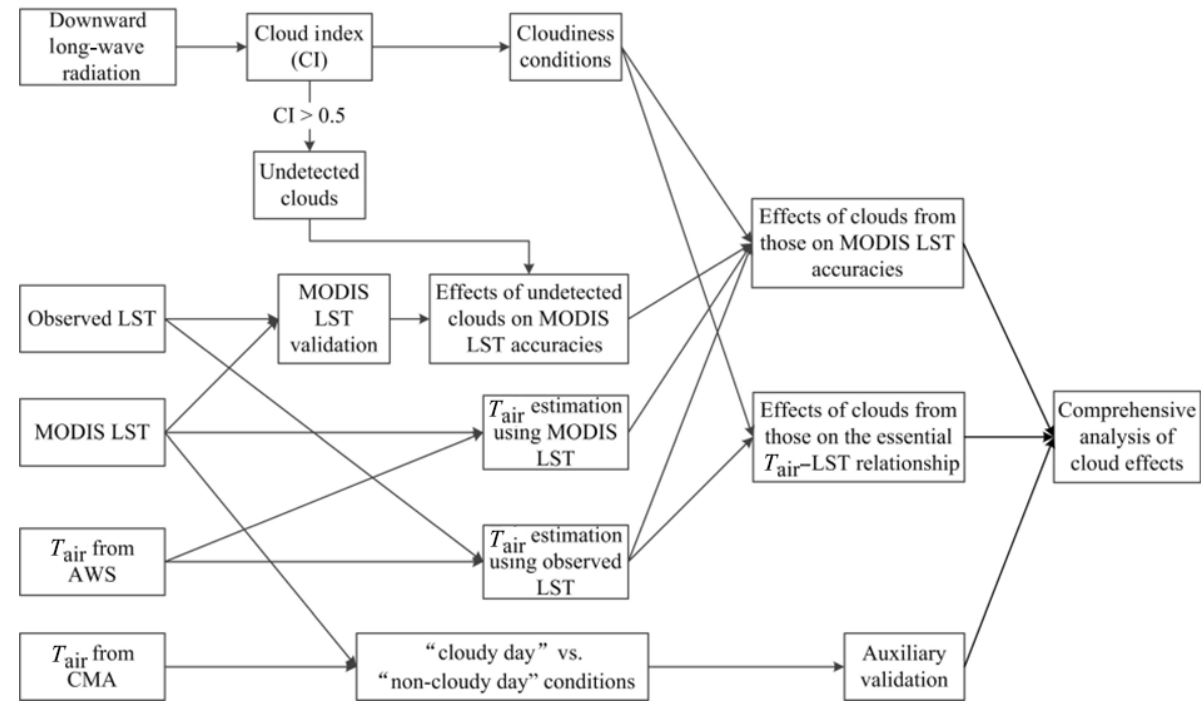

Figure 2. Flow chart describing the analysis and validation of cloud effects on air temperature estimation using MODIS LST in this study.

al., 2016). Compared with the complex models such as neural network and random forests, which introduce uncertainties because they have a much larger number of parameters, the linear regression model has the advantage of being easy to interpret and was most commonly used in previous studies (Zhang et al., 2011; Benali et al., 2012; Lin et al., 2012). In addition, an individual linear fit is built for each AWS or CMA station to make the relationship between $T_{\text {air }}$ and LST as locally accurate as possible and thus, variables indicating spatial coordinates (longitudes and latitudes) and land cover (e.g., NDVI) are not used. Therefore, the linear regression model using LST as the single independent variable is cho-

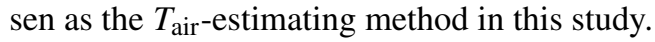

\subsection{Testing cloud effects by the observed LST}

Large MODIS LST errors may exist due to undetected clouds, and cloud effects are first tested using the groundmeasured LST. In this way, we can explore the direct effects of clouds on $T_{\text {air }}$ estimation using LST. The tests are conducted by constraining cloudiness conditions. Target $T_{\text {air }}$ values in most studies are daily (max, mean, or min) values, but instantaneous cloudiness is meaningless. In this study, the daily mean CI value is used as a cloudiness indicator. To ensure a sufficient number of samples, nine types of conditions with daily mean CI values $\leq 0.2,0.3, \ldots, 0.9$ and 1.0 are employed, indicating that the cloudiness constraints vary from highly clear conditions (daily mean $\mathrm{CI} \leq 0.2$ ) to fully mixed conditions, with many highly cloudy days included (daily mean $\mathrm{CI} \leq 1.0$ ). For each condition, $T_{\max }$ and $T_{\min }$ are regressed using daytime (13:30 LT, Aqua) and nighttime (22:30 LT, Terra) observed LST through a simple linear regression, and estimation accuracies are computed. The rootmean-square error (RMSE) and mean absolute error (MAE) are used as the accuracy measurements. Cloud effects are evaluated based on the variation of the estimation accuracies under different cloudiness conditions. Comparisons of $T_{\max }$ and $T_{\min }$ estimations can reveal further implications of cloud effects.

\subsection{Determining cloud effects through comparisons using MODIS and the observed LST}

Once the effects of clouds on $T_{\text {air }}$ estimations using observed LST are confirmed, cloud effects on $T_{\text {air }}$ estimation using MODIS LST can be explored more directly. Apart from affecting the relationship between $T_{\text {air }}$ and MODIS LST, clouds can degrade the MODIS LST accuracy and further reduce estimation accuracies. Such effects, when they are present, can be explored by comparing changes in estimation accuracy levels between observed LST and MODIS LST. Here, $T_{\text {air }}\left(T_{\min }\right.$ and $\left.T_{\max }\right)$ estimations for nine kinds of CI conditions are conducted using MODIS LST and observed LST (at the corresponding MODIS time). The results are analyzed based on comparisons.

\subsection{Exploring cloud effects based on observations from meteorological stations}

In practice, only daily observations can be easily obtained from meteorological stations, and cloudiness observations are usually not provided. In this study, only daily $T_{\max }$ and $T_{\min }$ data are obtained from the 92 CMA stations. Nonetheless, daily cloudiness levels can be partly evaluated from four MODIS observations for each day (two from Terra and two from Aqua). Then, comparisons of $T_{\text {air }}$ estimation for two distinct cloudiness conditions are drawn.

Two conditions ("cloudy day" and "non-cloudy day") are defined based on four instantaneous MODIS observations 

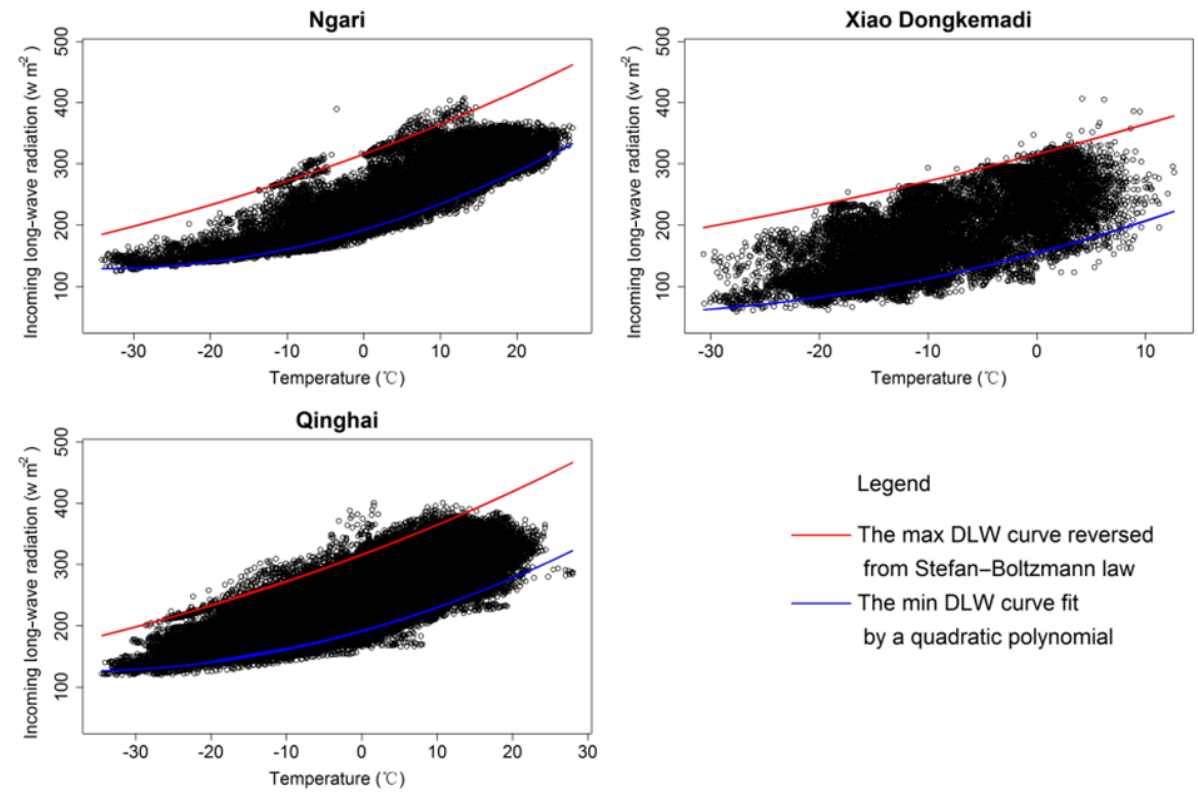

Figure 3. The distribution of observed downward long-wave radiation (DLW) under different air temperatures. The red line represents the max DLW curve reversed from the Stefan-Boltzmann law. The blue line is the min DLW curve fitted by a quadratic polynomial.

Table 2. Undetected MODIS LST clouds at three AWSs.

\begin{tabular}{lrrrr}
\hline Site & \multicolumn{4}{c}{ Ratio of undetected cloudy records } \\
\cline { 2 - 5 } & $\begin{array}{r}\text { Terra day } \\
(\%)\end{array}$ & $\begin{array}{r}\text { Terra night } \\
(\%)\end{array}$ & $\begin{array}{r}\text { Aqua day } \\
(\%)\end{array}$ & $\begin{array}{r}\text { Aqua night } \\
(\%)\end{array}$ \\
\hline Ngari & 5 & 3 & 3 & 15 \\
Xiao & 12 & 15 & 11 & 37 \\
Dongkemadi & 3 & 20 & 3 & 50 \\
Qinghai & 7 & 13 & 6 & 34 \\
\hline Average & & & & \\
\hline
\end{tabular}

for each day for both the $T_{\max }$ and $T_{\min }$ estimation using Aqua daytime LST and Terra nighttime LST, respectively. For "non-cloudy day" conditions, all four MODIS cloudiness observations are constrained as non-cloudy. For the "cloudy day" condition of the $T_{\max }$ estimation, Aqua daytime observations are constrained as non-cloudy to obtain the available LST, and Terra daytime observations are constrained as cloudy to make cloud effects as strong as possible. However, the Aqua nighttime and Terra nighttime observations are not constrained to obtain sufficient samples. For the "cloudy day" condition of the $T_{\min }$ estimation, the Terra nighttime observations are constrained as non-cloudy to obtain the available LST, whereas the Aqua nighttime observations are not constrained to obtain sufficient samples. Both Aqua daytime and Terra daytime observations are constrained as cloudy to make the cloud effects as strong as possible. $T_{\max }$ and $T_{\min }$ estimation accuracies are then compared under "cloudy day" and "non-cloudy day" conditions.

\section{Results}

\subsection{Cloud index estimation and the undetected clouds of MODIS}

Figure 3 shows that the maximum and minimum $L_{\mathrm{d}}$ curves effectively frame $L_{\mathrm{d}}$ variation for each air temperature. The CI values of all of the observations are then computed.

For each of the four overpass times of MODIS LST, a rate of undetected cloudy records can be determined using CI values (Table 2). The ratio of undetected cloudy records ranges from 3 to $50 \%$ with a fully averaged ratio of $15 \%$. This agrees well with the reported value of $\sim 15 \%$, which was computed based on a consistency comparison between MODIS and Lidar (Ackerman et al., 2008).

\subsection{MODIS LST validation under different cloud conditions}

The accuracy of MODIS LST can be affected by undetected cloudy pixels (Westermann et al., 2012; Shamir and Georgakakos, 2014). Figure 4 shows that after removing cloudy cases, the validation accuracies of all three sites present obviously lower MAE values and a better fit line slope. Improvements in accuracy for six ( 2 pass times $\times 3$ stations) nighttime cases range from 0.1 to $0.9^{\circ} \mathrm{C}$. However, no significant accuracy improvements were found after removing cloudy cases for daytime MODIS LST (Fig. 5). Only slightly better or comparative MAEs $\left(\leq 0.1{ }^{\circ} \mathrm{C}\right)$ were obtained.

This indicates that the accuracy of MODIS nighttime LST is more negatively affected by undetected clouds than that for daytime. The relatively weak influences of undetected 
(a)
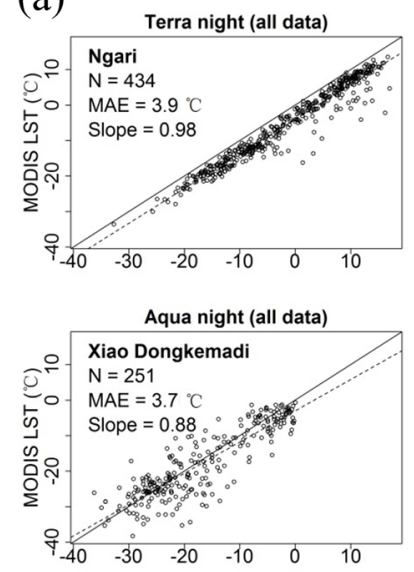

(b)
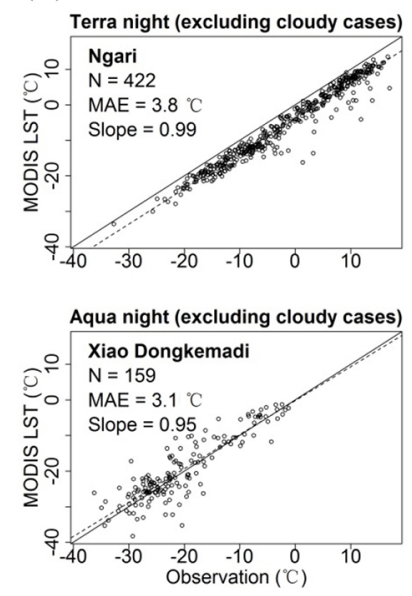
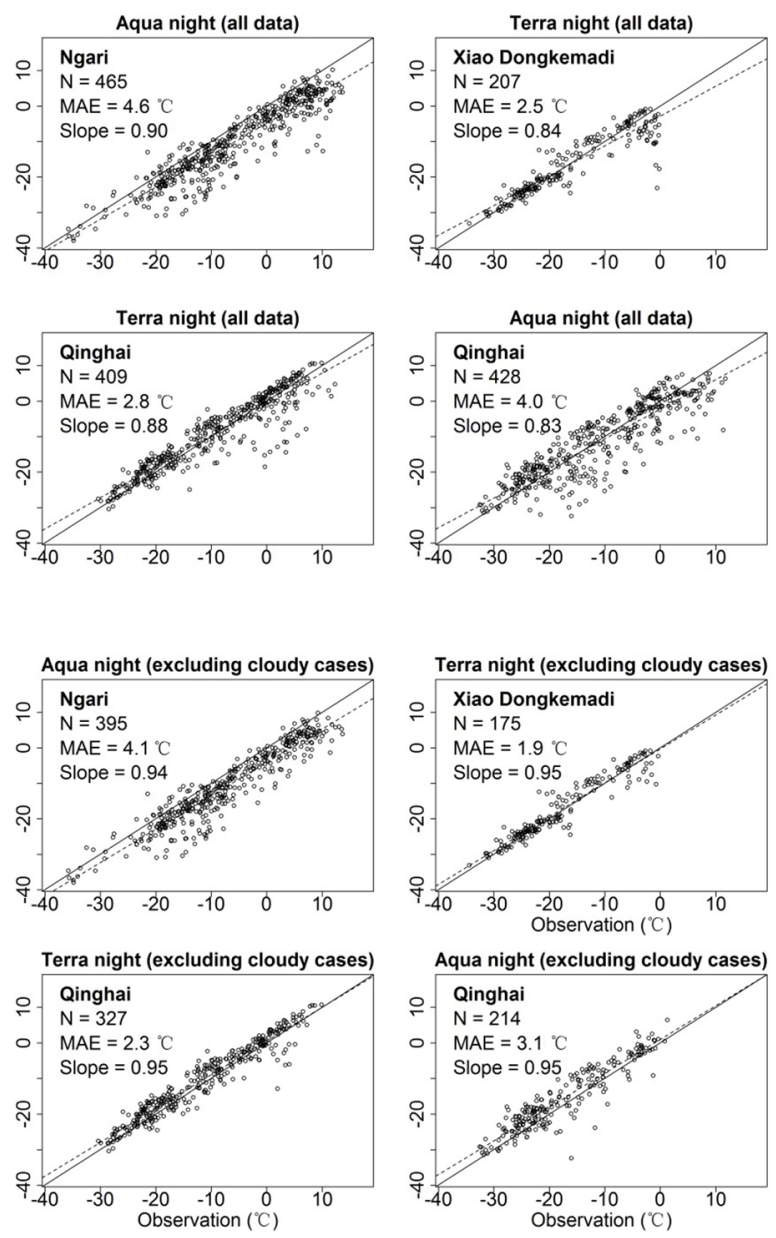

Figure 4. Validation of MODIS nighttime LST before (a) and after (b), excluding cloudy cases.

clouds on daytime LST is mainly due to obviously lower erroneous rates of cloud detection compared to those of nighttime LST. Erroneous rates of MODIS nighttime cloud detection are clearly larger than those for the daytime, though not in the case of the Terra LST observed for Ngari. This can be largely attributed to differences in cloud-detection methods used for daytime and nighttime. The cloud-detection algorithm of MODIS is considered to present more confidence for the daytime than for the nighttime due to the absence of reflected solar radiation during nighttime (Ackerman et al., 1998). This finding is consistent with previous studies showing that more than $40 \%$ of the observed cloudy days are identified as clear days by MODIS at polar summer nighttime (Østby et al., 2014).

\subsection{The effects of clouds on $\boldsymbol{T}_{\text {air }}$ estimation based on ground-observed LST}

Figure 6 shows the accuracy of $T_{\text {air }}$ estimations based on ground-observed LST under different cloudiness conditions across the three sites. For $T_{\max }$, estimation errors including
RMSE and MAE continually increased as the cloudiness condition constraints eased. The increase in RMSE/MAE values for clear conditions (daily mean $\mathrm{CI} \leq 0.2$ ) compared with totally mixed conditions (daily mean $\mathrm{CI} \leq 1$ ) was 1.3/1.0, 0.8/0.8, and $1.6 / 1.6^{\circ} \mathrm{C}$ for the Ngari, Xiao Dongkemadi, and Qinghai stations, respectively. In contrast, for $T_{\min }$, accuracy variation is consistently mild across the three sites, presenting RMSE/MAE changes of 0.1/0.0, 0.1/0.0, and $0.7 / 0.6^{\circ} \mathrm{C}$ for the Ngari, Xiao Dongkemadi, and Qinghai stations, respectively. It should be noted that when the "cloudiness condition" exceeds $0.6(x>0.6)$, the sample number no longer varies and due to the limited number of samples, the variation of $T_{\max }$ and $T_{\min }$ estimation accuracy is rather flat.

As expected for cases based on ground-observed LST, the $T_{\max }$ estimation is significantly affected by cloud conditions, but clouds have a limited effect on the $T_{\min }$ estimation compared to $T_{\max }$. This interesting finding can be explained by mechanisms through which clouds affect nighttime and daytime surface temperatures. In the daytime, LST is significantly influenced by solar heating. The presence of clouds 

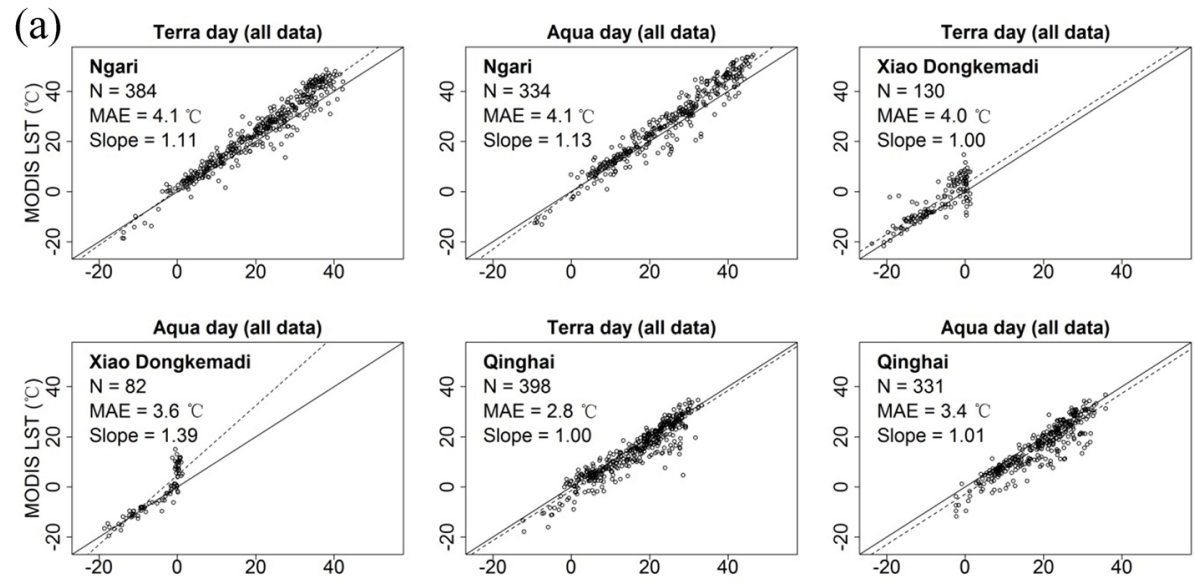

(b)
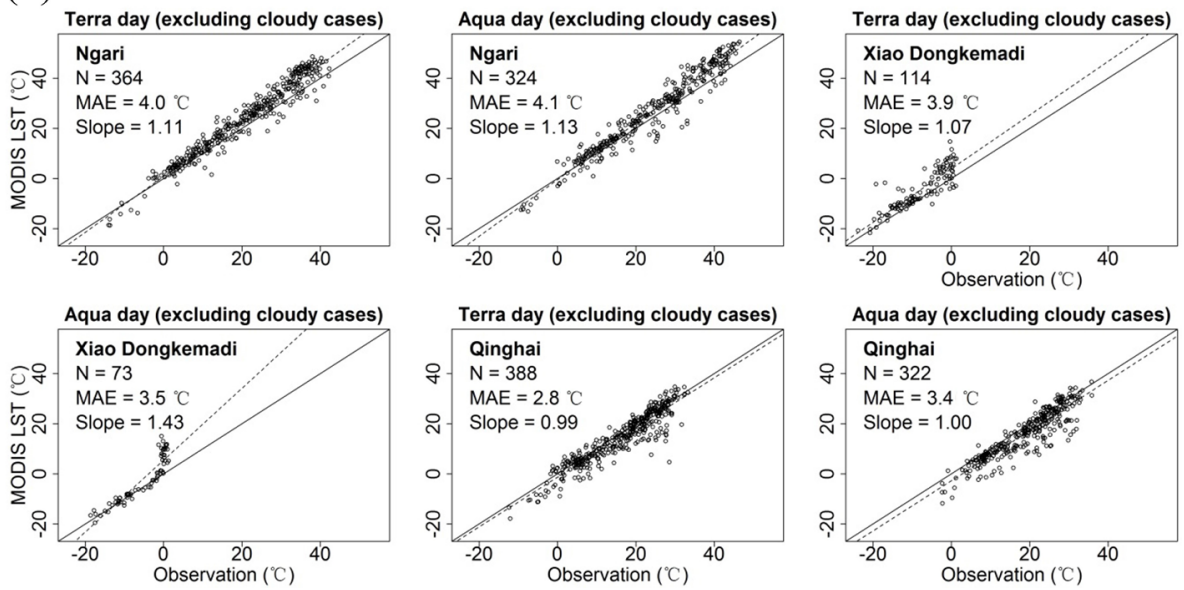

Figure 5. Validation of MODIS daytime LST before (a) and after (b), excluding cloudy cases.

can screen out solar radiation and cool the surface. Much larger differences between LST and $T_{\text {air }}$ have been observed under cloudy days than under clear conditions (Gallo et al., 2011). At night, the surface can also present warming effects from clouds due to reflected infrared long-wave radiation. However, such effects are not typically significant because the net effect of clouds on surface downward long-wave radiation is much less pronounced than nighttime solar cooling effects in most cases, as indicated by Dai et al. (1999).

\subsection{The effects of clouds on $T_{\text {air }}$ estimation based on MODIS LST}

Figure 7 compares cloud effects on $T_{\min }$ and $T_{\max }$ estimations using MODIS and observed LST. First, despite rather mild effects of cloud conditions on $T_{\min }$ estimation based on ground-observed LST, cloud effects based on MODIS LST are clearly much more significant. For cases based on MODIS LST, increases in RMSE between clear (daily mean $\mathrm{CI} \leq 0.2$ ) and mixed conditions (daily mean $\mathrm{CI} \leq 1.0$ ) are 0.5 , 0.8 , and $1.8^{\circ} \mathrm{C}$ for the Ngari, Xiao Dongkemadi, and Qinghai stations, respectively. However, cloud effects for cases based on observed LST are significantly lower with corresponding values of $0.0,-0.1$, and $0.2{ }^{\circ} \mathrm{C}$.

This indicates that $T_{\min }$ estimations based on MODIS LST are greatly affected by clouds. This seems counterintuitive, as it has been shown that $T_{\min }$ estimations based on ground-observed LST are not significantly affected by clouds (Fig. 6). Thus, the most probable driving factor may be the relatively large amount of undetected clouds present in MODIS nighttime LST. As daily cloud indexes increase, more undetected cloudy cases may be introduced, thus reducing the accuracy of MODIS nighttime LST (Fig. 4 and Table 2).

Figure 8 (upper section) supports the conclusion that under clear conditions the undetected clouds are rare, and limited accuracy improvements are achieved by removing the few cloudy MODIS LST records; however, as daily CI constraints ease to 0.5 when cloudy records account for a substantial proportion, obvious improvements appear, and the final accuracies are much closer to and are even better than those based on ground-observed LST. 

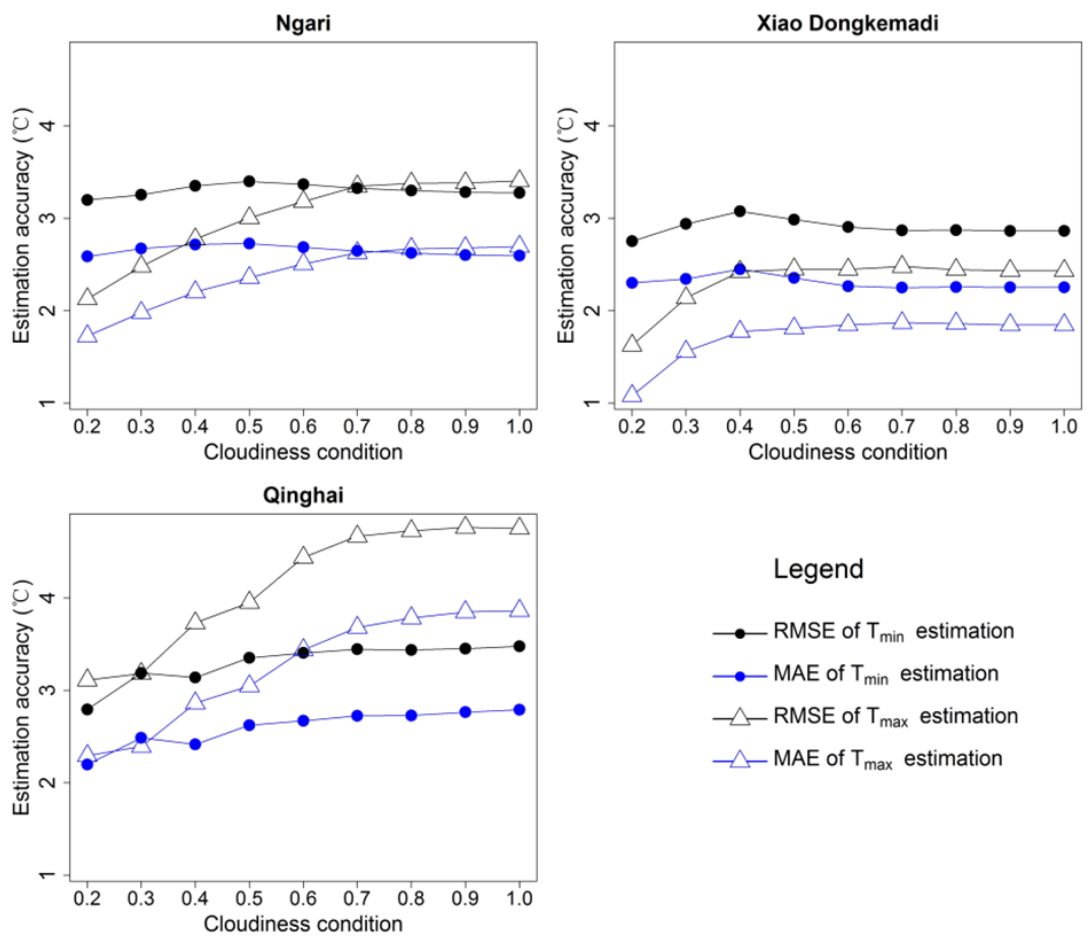

\section{Legend}

$\longrightarrow$ RMSE of $\mathrm{T}_{\min }$ estimation

$\longrightarrow$ MAE of $T_{\min }$ estimation

$\triangle$ RMSE of $T_{\max }$ estimation

$\neg-$ MAE of $T_{\max }$ estimation

Figure 6. Accuracies (RMSE and MAE) of $T_{\max }$ and $T_{\min }$ estimations based on ground-measured LST under different cloudiness conditions across the three sites. The "cloudiness condition" is the constraining condition of the daily averaged cloudiness index (CI). For example, a cloudiness condition of 0.2 denotes a constraining daily mean of $\mathrm{CI} \leq 0.2$.
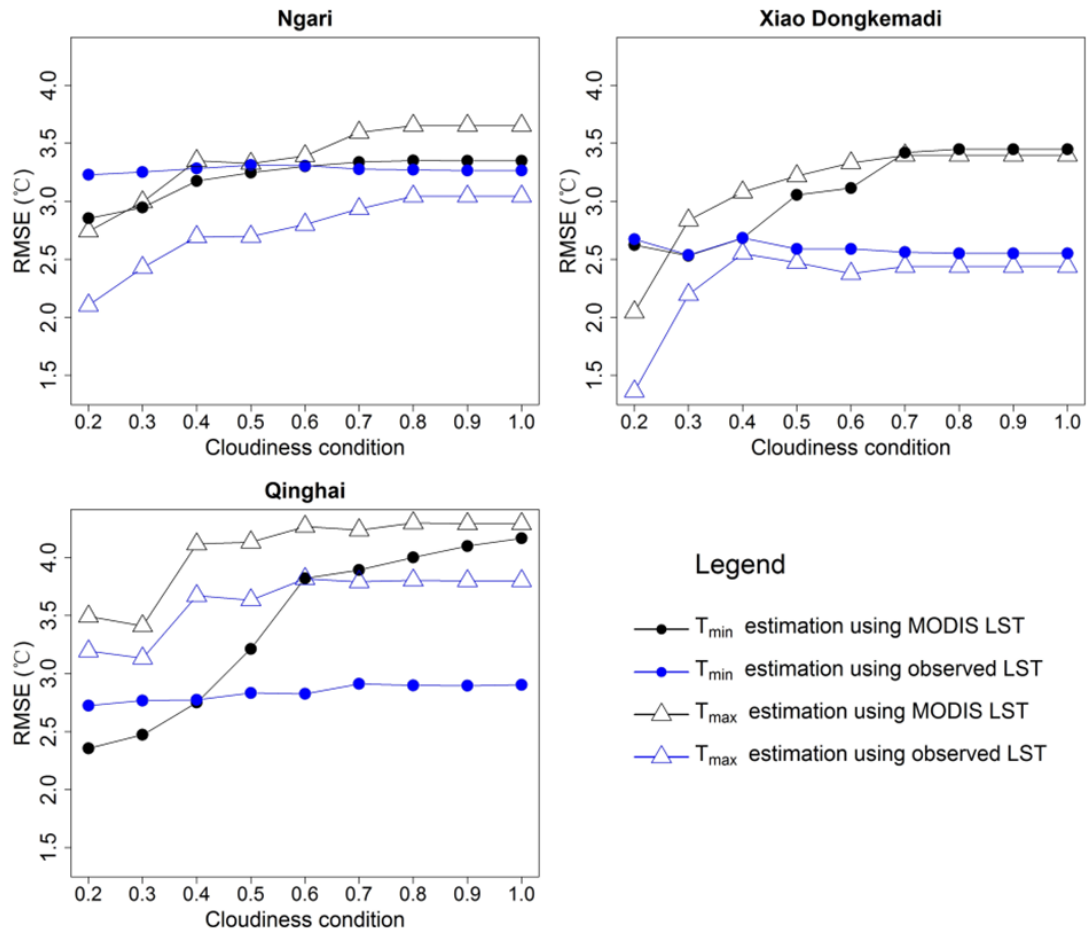

Legend

$\longrightarrow T_{\min }$ estimation using MODIS LST

$\longrightarrow T_{\min }$ estimation using observed LST

$\triangle T_{\max }$ estimation using MODIS LST

$\neg-T_{\max }$ estimation using observed LST

Figure 7. Accuracies (RMSE) of $T_{\max }$ and $T_{\min }$ estimations based on ground-measured or MODIS LST under different cloudiness conditions for the three AWSs. The "cloudiness condition" is the constraining condition of the daily averaged cloudiness index (CI). For example, a cloudiness condition of 0.2 denotes a constraining daily mean of $\mathrm{CI} \leq 0.2$. 

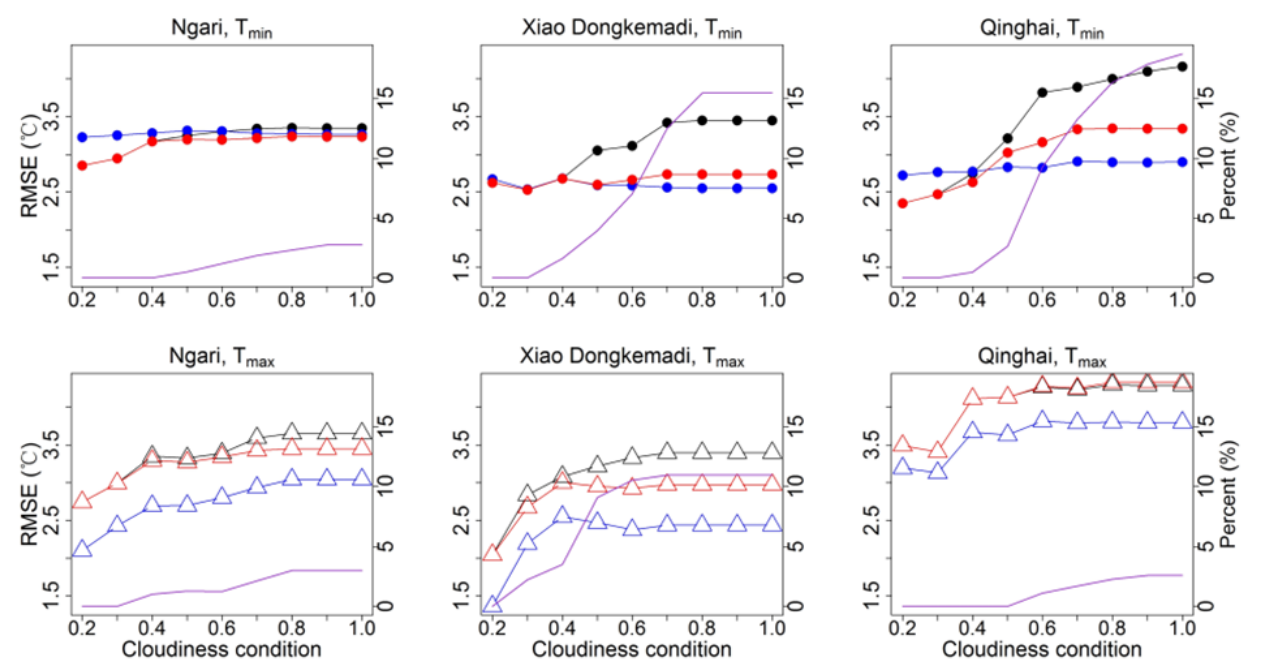

Legend

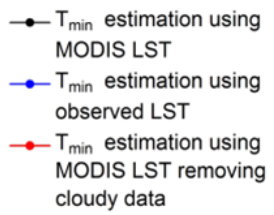

$$
\begin{aligned}
& T_{\max } \text { estimation using } \\
& \text { MODIS LST } \\
& \text { observed LST } \\
& \text { max } \\
& \text { MODIS LST removing } \\
& \text { cloudy data }
\end{aligned}
$$

Figure 8. Comparisons between $T_{\min }$ and $T_{\max }$ estimation accuracies based on MODIS LST, MODIS LST without cloudy data, and observed LST under different cloudiness conditions for the three AWSs.

Unlike that of $T_{\min }$, the accuracy variation of $T_{\max }$ estimation based on MODIS LST shows trends that are highly consistent with those of cases based on ground-observed LST for all of the three sites. As with cases based on ground-observed LST, $T_{\max }$ estimations based on MODIS LST are found to be greatly affected by clouds. In addition, increases in accuracy level differences between clear and mixed conditions are much less pronounced compared to those of $T_{\min }$, where difference values are only $0.0,0.2$, and $0.3^{\circ} \mathrm{C}$ for the Ngari, Xiao Dongkemadi, and Qinghai stations, respectively $\left(T_{\max }\right.$ estimation based on MODIS LST vs. that based on groundobserved LST).

However, the accuracy levels achieved from MODS LST after removing cloudy records are obviously lower than those based on ground-observed LST under all cloudiness conditions. This raises questions regarding what this difference in accuracy can be attributed to. Dominant factors may not be undetected clouds, as was the case for $T_{\min }$. As shown in Fig. 8 (lower section), the removal of cloudy records had somewhat moderate effects on accuracy levels. This may be largely due to much lower erroneous rates of cloud identification for MODIS daytime LST. The obviously lower number of undetected clouds compared to nighttime LST values for the Ngari and Qinghai stations results in relatively limited accuracy improvements. The relatively large decrease in estimation errors for the Xiao Dongkemadi station is mainly due to unexpectedly higher amounts of undetected clouds in MODIS daytime LST for that site (Table 2 and Fig. 8).
Furthermore, even under clear conditions, the accuracy of $T_{\max }$ estimations based on MODIS LST is remarkably lower than that based on ground-observed LST (Fig. 7). Thus, the decrease in accuracy levels relative to cases based on groundobserved LST may be caused by factors other than undetected clouds. This seems odd, especially given that the accuracies of $T_{\min }$ estimations based on MODIS LST are very close to or even better than those based on observed LST under clear conditions (Fig. 7).

\subsection{Effects of clouds on $T_{\text {air }}$ estimation based on MODIS LST and CMA observations}

Figure 9 shows the estimation accuracies of $T_{\text {air }}$ based on MODIS LST for non-cloudy and cloudy conditions. For the $T_{\max }$ estimation, clouds appear to have moderate effects on estimation accuracies, where $88 \%$ of the 92 stations obtained lower RMSEs based on samples from "non-cloudy" conditions relative to cloudy cases. RMSE values are reduced by an average of $0.54^{\circ} \mathrm{C}$. In contrast, effects of clouds on $T_{\min }$ estimations are much more significant: the RMSEs of $98 \%$ of stations are reduced by an average of $1.44{ }^{\circ} \mathrm{C}$. Though hourly observations in the data for CMA stations are lacking, the results for the cloud tests are highly consistent with those based on half-hourly AWS observations.

Furthermore, a comparison between the $T_{\max }$ and $T_{\min }$ estimation results based on MODIS LST and CMA observations shows that under cloudy conditions $T_{\max }$ estimations 

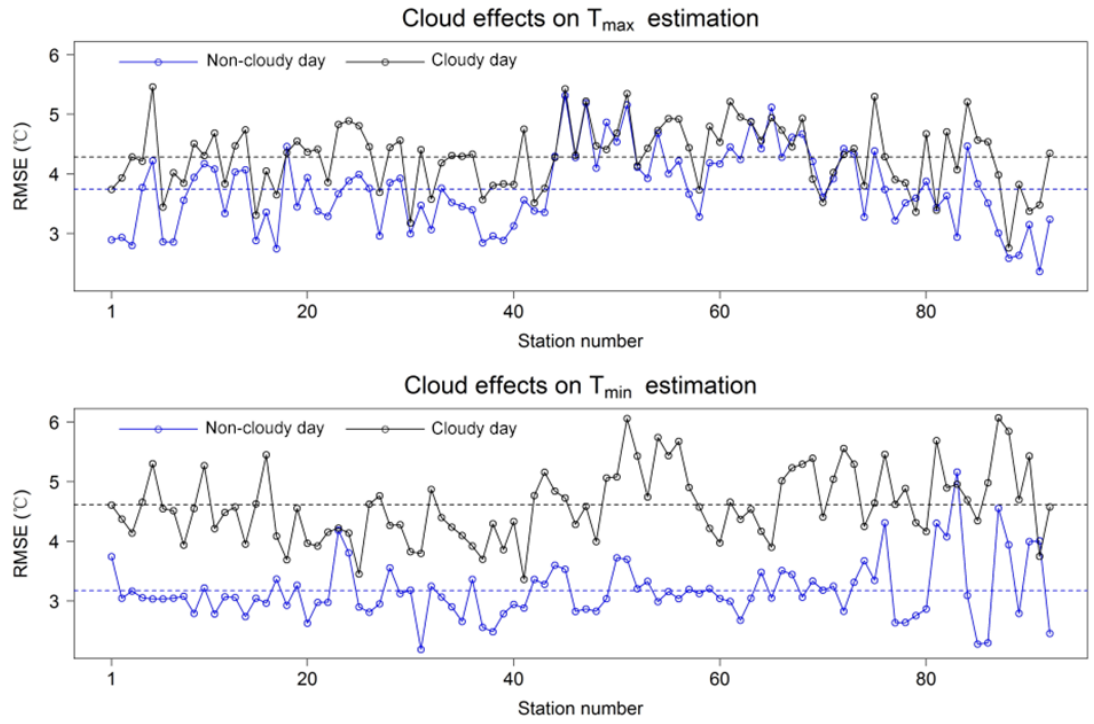

Figure 9. Comparisons of $T_{\text {air }}$ estimation accuracy levels based on MODIS LST and CMA observations for "non-cloudy day" and "cloudy day" conditions.

(the mean RMSE is $4.3^{\circ} \mathrm{C}$ ) achieve generally higher levels of accuracy than $T_{\min }$ estimations (the mean RMSE is $4.6^{\circ} \mathrm{C}$ ), whereas non-cloudy conditions produce the opposite effect $\left(3.7\right.$ vs. $\left.3.2{ }^{\circ} \mathrm{C}\right)$. This illustrates a potentially stronger negative effect of cloud on $T_{\max }$ estimation than on $T_{\min }$ estimation.

\section{Discussion}

\subsection{Differences in the effects of clouds on $T_{\min }$ and $T_{\max }$ estimations based on MODIS LST}

From MODIS LST and daily CMA observations, different cloud effects between $T_{\max }$ and $T_{\min }$ estimations can be identified from Fig. 9. Under cloudy conditions, the existence of more undetected cloudy records in MODIS nighttime LST largely degrades the LST accuracy and results in obviously lower $T_{\min }$-estimation accuracy levels. However, why the $T_{\min }$ estimations clearly outperform $T_{\max }$ under clear conditions (non-cloudy day conditions) when both are free of cloud effects remains unknown. One may argue that the socalled "clear" conditions are based on only four satellite instantaneous observations and that actual cloudiness conditions may still be cloudy. Although this is true, our study shows that even under clear conditions the accuracy of $T_{\max }$ estimations based on daytime MODIS LST is much lower than those based on observed LST, whereas the $T_{\min }$ estimation based on nighttime MODIS LST shows comparable or even superior accuracy.

From our previous analysis, we can attribute this difference in estimation accuracy between $T_{\min }$ and $T_{\max }$ to differences between daytime and nighttime MODIS LST. Much lower levels of MODIS daytime LST accuracy than those of nighttime have been found in previous studies (Yu and $\mathrm{Ma}$, 2011; Krishnan et al., 2015; Min et al., 2015), and the validation tests shown in Figs. 4 and 5 also support this conclusion. This precision bias is most likely attributable to scale issues (Wan et al., 2002; Wan, 2008). Single point measurements are difficult to make representative of the $1 \mathrm{~km}$ MODIS pixel when ground surfaces are complex (Hall et al., 2008; Coll et al., 2009). Many studies have shown that MODIS daytime LST presents obviously lower levels of validation accuracy than nighttime LST due to high levels of daytime LST heterogeneity (Wang et al., 2008; Coll et al., 2009). In the daytime, cloud and hill shadows within pixels can produce considerable LST heterogeneities, while at night, the ground surface becomes cool and more homogeneous when free of solar heating uncertainties (Wang et al., 2008). Oyler et al. (2016) also show that daytime LST exhibits more spatial variation than $T_{\text {air }}$, while nighttime LST follows similar spatial patterns as $T_{\text {air }}$, as demonstrated in this study.

In addition, it should be noted that clouds also have substantial effects on $T_{\max }$ estimation. Thus, it can be concluded that the frequently reported lower estimation accuracies of $T_{\max }$ based on MODIS daytime LST compared to those of $T_{\min }$ based on nighttime LST (Zhang et al., 2011; Benali et al., 2012; Zhu et al., 2013; Oyler et al., 2016) are mainly due to the mixed effects of clouds and the relatively low daytime LST accuracies.

To further prove this, four CMA stations (Fig. 10) presenting the largest reduction in RMSE values after imposing clear conditions are selected for our $T_{\min }$ and $T_{\max }$ estimations. They can represent practical application conditions where only daily meteorological observations can be obtained. 
For $T_{\max }$ estimation (Fig. 11), it is evident that forcing clear conditions has somewhat limited effects on estimation performance. The samples collected under "cloudy day" conditions include outliers far from the fit line derived using samples under "non-cloudy day" conditions. However, the "non-cloudy day" samples still appear rather dispersed, with many samples positioned far from the fit line, and especially in the case of stations 89 and 41 . This may illustrate mixed effects of both clouds and LST accuracies to some degree.

In contrast, the results of the $T_{\min }$ estimation are somewhat inspiring. As shown in Fig. 12, a number of cold-biased outliers that may be undetected cloudy records are captured by employing cloudy conditions. More importantly, the "noncloudy day" condition samples achieve a much better fit. This not only demonstrates that undetected cloudy records are ubiquitous in MODIS nighttime LST and that amounts can often be quite large, but also that the influence of clouds on $T_{\min }$ estimations with true LST (i.e., without undetected clouds) is not substantial. Though the actual cloudiness conditions are rather unpredictable and quite a few "good" samples around the "non-cloudy day" fit line are also included in the "cloudy day" group, we consider constraining all four MODIS observations for each day as non-cloudy as an efficient way to build a good fit among $T_{\min }$ estimations using MODIS nighttime LST, as long as the amount of valid samples is sufficient. This method can benefit studies requiring accurate $T_{\min }$ estimations based on remotely sensed LST.

\subsection{Uncertainty and error sources}

Emissivity issues may have caused the observed LST computation errors. Constant emissivity values for the Ngari and Qinghai stations are used in our study, although this may not be reasonable for non-growing seasons. However, the sensitivity experiments show that the influence of emissivity values is not significant.

The $\leq 15$-min discrepancy may introduce uncertainties in data that intersect $T_{\text {air }}$ and MODIS and observed LST. Its influence is considered to be insignificant. Nighttime LST changes gently and half-hourly observations can be used for MODIS LST validation as indicated in Wang et al. (2008). $T_{\text {air }}$ also responds relatively slowly to LST, and MODIS daytime LST shows a strong relationship to $T_{\text {air }}$ at a similar time discrepancy level ( $\leq 12 \mathrm{~min})$ to that shown by Williamson et al. (2013). Spatial heterogeneities within MODIS pixels of AWS may pose problems. As shown in Fig. 1, such problems may not be severe, as land cover within the pixels of the three AWSs appears to be largely homogeneous. The data quality of MODIS LST does not receive sufficient consideration in this study. MODIS LST production involves the use of internal data quality flags and previous studies demonstrate that data quality is related to cloud contamination (Williamson et al., 2013; Østby et al., 2014).

The validation accuracy of MODIS LST is affected by data quality (Krishnan et al., 2015). However, rigid data quality

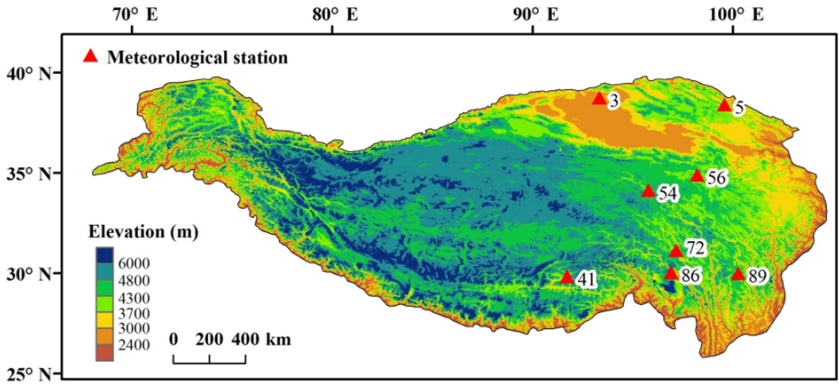

Figure 10. Locations of four representative CMA stations for $T_{\min }$ (Nos. 54, 56, 72, 86) and $T_{\max }$ (Nos. 3, 5, 41, 89) estimations.

constraints may severely decrease sample sizes due to the relatively short observation periods (1-2 years) used. This study presents results of general quality status and extremely low-quality data $(\mathrm{QC}=3)$ have been removed. Other factors, including wind speeds and sensor view zenith angles, may affect results related to MODIS LST validation and the relationship between $T_{\text {air }}$ and LST. According to Wang et al. (2008), the validation results are not or are weakly affected by wind speed and the sensor view zenith angle. Wind speed has a limited effect on the $T_{\text {air }}$-LST relationship, as shown by Gallo et al. (2011).

In addition, the results shown here are highly consistent across the three AWSs dominated by three types of land cover, thus indicating that our results may be highly representative and that other factors may not have played a key role.

\section{Conclusion}

Cloud effects on $T_{\min }$ and $T_{\max }$ estimations according to MODIS LST are analyzed based on detailed ground-based observations from three valuable AWSs and based on data from 92 CMA stations over the TP. Cloudiness is quantified using an efficient method based on ground measurements of air temperature and downwelling long-wave radiation. Comparisons made between in situ cloudiness observations and MODIS-claimed clear-sky records show that erroneous rates of MODIS nighttime cloud detection are obviously larger than those for the daytime. Our MODIS LST validation for different cloudiness constraining conditions reveals that the accuracy of MODIS nighttime LST is severely affected by undetected clouds. However, the accuracies of MODIS daytime LST do not seem to be influenced by undetected clouds.

Cloud effect tests show that $T_{\min }$ estimations based on MODIS LST are mainly affected by large errors introduced by undetected clouds in nighttime LST. However, clouds mainly influence $T_{\max }$ estimation by affecting the relationship between $T_{\max }$ and daytime LST. The effects of undetected clouds in daytime LST are relatively weak. Frequently reported errors in $T_{\max }$ estimations based on daytime LST 

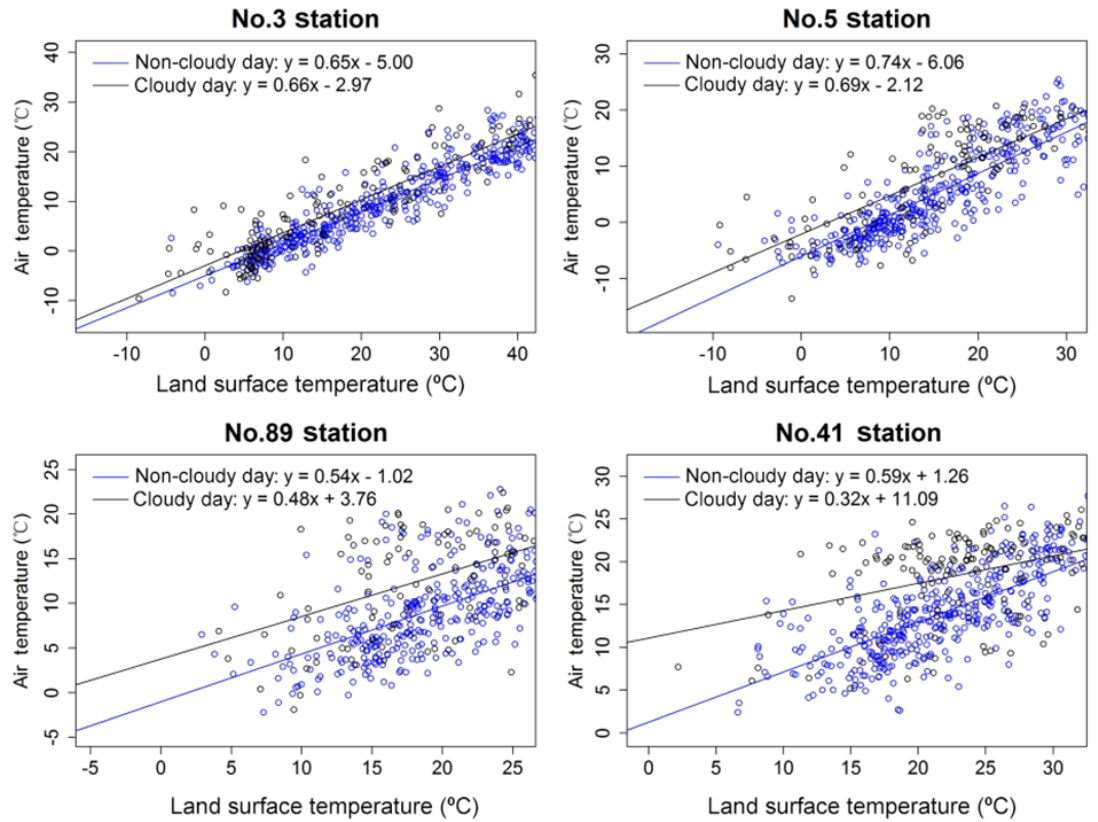

Figure 11. Comparisons of $T_{\max }$ estimation accuracy between "cloudy day" and "non-cloudy day" conditions at four meteorological stations presenting the largest decline in RMSE.
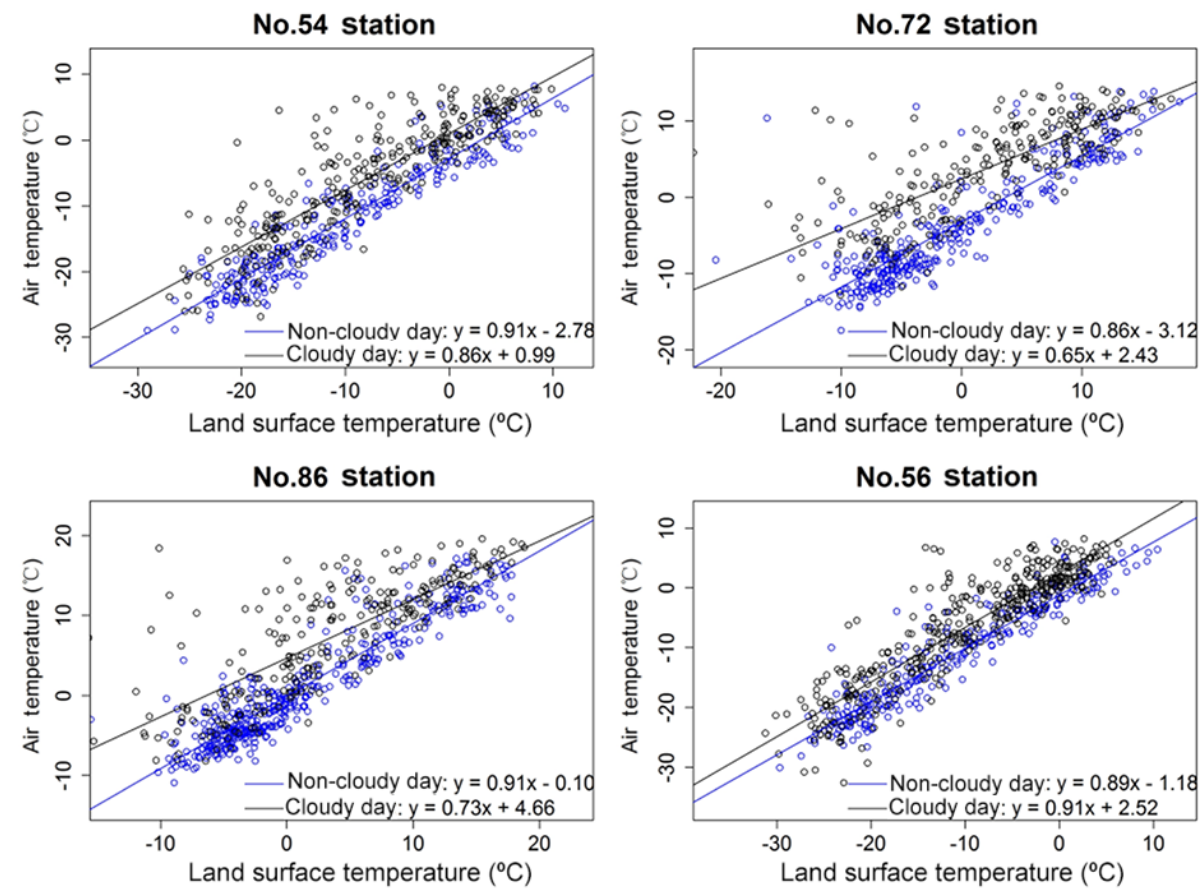

Figure 12. Comparisons of $T_{\min }$ estimation accuracy between "cloudy day" and "non-cloudy day" conditions at four meteorological stations presenting the largest decline in RMSE.

that are larger than those of $T_{\min }$ based on nighttime LST may be largely attributed to relatively large errors of MODIS daytime LST resulting from scale issues. Tests based on CMA station observations further validate our results and show that constraining all four MODIS observations per day as non- cloudy helps rule out undetected cloudy records while building good $T_{\min }$ estimation fit.

This study presents useful findings on the key effects of clouds on $T_{\text {air }}$ estimation based on MODIS LST that can alleviate problems of severe data sparseness over the TP. More 
efficient cloud detection methods for MODIS nighttime LST are needed for $T_{\min }$ estimations. $T_{\max }$ estimation based on daytime LST is rather challenging due to the complex effects of daily cloudiness conditions in combination with scale issues.

\section{Data availability}

The data of Xiao Dongkemadi station are available upon request to the Tanggula Station for Cryosphere Environment Observation and Research (hxb@lzb.ac.cn). The data of Ngari station are available upon request to the Ngari Station for Desert Environment Observation and Research (ldt@itpcas.ac.cn). The data of Qinghai station can be downloaded from AsiaFlux (AsiaFlux, 2016). The daily air temperature data of meteorological stations are available at http: //data.cma.cn (Chinese Meteorology Administration, 2014).

Author contributions. Lide Tian and Xiaobo He observed and provided the data of stations Ngari and Xiao Dongkemadi, respectively. Fan Zhang and Guoqing Zhang gave many valuable suggestions to improve the article. Hongbo Zhang designed the experiments and wrote the article.

Acknowledgements. This work was supported by the Chinese Academy of Sciences "Strategic Priority Research Program (B)" (Grant No. XDB03030300) and by the National Natural Science Foundation of China (Grant Nos. 41422101, 41271079, 41130638). We thank the Tanggula Station for Cryosphere Environment Observation and Research and the Ngari Station for Desert Environment Observation and Research for providing ground measurements of long-wave radiation and air temperature data. We would like to thank Yanhong Tang for providing the ground measurements for the Qinghai station. We are grateful to the Chinese Meteorology Administration for providing air temperature data.

Edited by: J. Huang

Reviewed by: two anonymous referees

\section{References}

Ackerman, S. A., Strabala, K. I., Menzel, W. P., Frey, R. A., Moeller, C. C., and Gumley, L. E.: Discriminating clear sky from clouds with MODIS, J. Geophys. Res.-Atmos., 103, 3214132157, doi:10.1029/1998jd200032, 1998.

Ackerman, S. A., Holz, R. E., Frey, R., Eloranta, E. W., Maddux, B. C., and McGill, M.: Cloud Detection with MODIS. Part II: Validation, J. Atmos. Ocean. Tech., 25, 1073-1086, doi:10.1175/2007JTECHA1053.1, 2008.
AsiaFlux: Qinghai Flux Research Site, available at: http://www. asiaflux.net, last access: June 2016.

Benali, A., Carvalho, A. C., Nunes, J. P., Carvalhais, N., and Santos, A.: Estimating air surface temperature in Portugal using MODIS LST data, Remote Sens. Environ., 124, 108-121, doi:10.1016/j.rse.2012.04.024, 2012.

Chinese Meteorology Administration: China daily ground climate dataset, available at: http://data.cma.cn, last access: April 2014.

Coll, C., Wan, Z., and Galve, J. M.: Temperature-based and radiance-based validations of the V5 MODIS land surface temperature product, J. Geophys. Res.-Atmos., 114, D20102, doi:10.1029/2009JD012038, 2009.

Dai, A., Trenberth, K. E., and Karl, T. R.: Effects of clouds, soil moisture, precipitation, and water vapor on diurnal temperature range, J. Climate, 12, 2451-2473, doi:10.1175/15200442(1999)012<2451:eocsmp>2.0.co;2, 1999.

Emamifar, S., Rahimikhoob, A., and Noroozi, A. A.: Daily mean air temperature estimation from MODIS land surface temperature products based on M5 model tree, Int. J. Climatol., 33, 31743181, doi:10.1002/joc.3655, 2013.

Fu, G., Shen, Z., Zhang, X., Shi, P., Zhang, Y., and Wu, J.: Estimating air temperature of an alpine meadow on the Northern Tibetan Plateau using MODIS land surface temperature, Acta Ecol. Sin., 31, 8-13, doi:10.1016/j.chnaes.2010.11.002, 2011.

Gallo, K., Hale, R., Tarpley, D., and Yu, Y.: Evaluation of the relationship between air and land surface temperature under clearand cloudy-sky conditions, J. Appl. Meteorol. Clim., 50, 767775, 2011.

Giesen, R., Van den Broeke, M., Oerlemans, J., and Andreassen, L.: Surface energy balance in the ablation zone of Midtdalsbreen, a glacier in southern Norway: interannual variability and the effect of clouds, J. Geophys. Res.-Atmos., 113, D21111, doi:10.1029/2008JD010390, 2008.

Good, E.: Daily minimum and maximum surface air temperatures from geostationary satellite data, J. Geophys. Res.-Atmos., 120, 2306-2324, doi:10.1002/2014JD022438, 2015.

Hall, D. K., Box, J. E., Casey, K. A., Hook, S. J., Shuman, C. A., and Steffen, K.: Comparison of satellite-derived and in situ observations of ice and snow surface temperatures over Greenland, Remote Sens. Environ., 112, 3739-3749, 2008.

Huang, J., Wang, T., Wang, W., Li, Z., and Yan, H.: Climate effects of dust aerosols over East Asian arid and semiarid regions, J. Geophys. Res.-Atmos., 119, 11398-11416, doi:10.1002/2014JD021796, 2014.

Huintjes, E., Sauter, T., Schröter, B., Maussion, F., Yang, W., Kropácek, J., Buchroithner, M., Scherer, D., Kang, S., and Schneider, C.: Evaluation of a coupled snow and energy balance model for Zhadang glacier, Tibetan Plateau, using glaciological measurements and time-lapse photography, Arct. Antarct. Alp. Res., 47, 573-590, 2015.

Jang, J.-D., Viau, A., and Anctil, F.: Neural network estimation of air temperatures from AVHRR data, Int. J. Remote Sens., 25, 4541-4554, 2004.

Kilibarda, M., Hengl, T., Heuvelink, G. B. M., Gräler, B., Pebesma, E., Perčec Tadić, M., and Bajat, B.: Spatio-temporal interpolation of daily temperatures for global land areas at 1 km resolution, J. Geophys. Res.-Atmos., 119, 2294-2313, doi:10.1002/2013JD020803, 2014. 
Krishnan, P., Kochendorfer, J., Dumas, E. J., Guillevic, P. C., Baker, C. B., Meyers, T. P., and Martos, B.: Comparison of in situ, aircraft, and satellite land surface temperature measurements over a NOAA Climate Reference Network site, Remote Sens. Environ., 165, 249-264, 2015.

Langer, M., Westermann, S., and Boike, J.: Spatial and temporal variations of summer surface temperatures of wet polygonal tundra in Siberia - implications for MODIS LST based permafrost monitoring, Remote Sens. Environ., 114, 2059-2069, doi:10.1016/j.rse.2010.04.012, 2010.

Lin, S. P., Moore, N. J., Messina, J. P., DeVisser, M. H., and Wu, J. P.: Evaluation of estimating daily maximum and minimum air temperature with MODIS data in east Africa, Int. J. Appl. Earth Obs., 18, 128-140, doi:10.1016/j.jag.2012.01.004, 2012.

Lin, X., Pielke Sr., R. A., Mahmood, R., Fiebrich, C. A., and Aiken, R.: Observational evidence of temperature trends at two levels in the surface layer, Atmos. Chem. Phys., 16, 827-841, doi:10.5194/acp-16-827-2016, 2016.

Min, W., Yueqing, L. I., and Zhou, J.: Validation of MODIS Land Surface Temperature Products in East of the QinghaiXizang Plateau, Plateau Meteorology, V34, 1511-1516, doi:10.7522/j.issn.1000-0534.2014.00082, 2015 (in Chinese).

Østby, T. I., Schuler, T. V., and Westermann, S.: Severe cloud contamination of MODIS Land Surface Temperatures over an Arctic ice cap, Svalbard, Remote Sens. Environ., 142, 95-102, doi:10.1016/j.rse.2013.11.005, 2014.

Oyler, J. W., Ballantyne, A., Jencso, K., Sweet, M., and Running, S. W.: Creating a topoclimatic daily air temperature dataset for the conterminous United States using homogenized station data and remotely sensed land skin temperature, Int. J. Climatol., 35, 2258-2279, 2015.

Oyler, J. W., Dobrowski, S. Z., Holden, Z. A., and Running, S. W.: Remotely Sensed Land Skin Temperature as a Spatial Predictor of Air Temperature across the Conterminous United States, J. Appl. Meteorol. Clim., 55, 1441-1457, doi:10.1175/JAMC-D15-0276.1, 2016.

Parmentier, B., McGill, B. J., Wilson, A. M., Regetz, J., Jetz, W., Guralnick, R., Tuanmu, M. N., and Schildhauer, M.: Using multitimescale methods and satellite-derived land surface temperature for the interpolation of daily maximum air temperature in Oregon, Int. J. Climatol., 35, 3862-3878, 2015.

Platnick, S., King, M. D., Ackerman, S. A., Menzel, W. P., Baum, B. A., Riedi, J. C., and Frey, R. A.: The MODIS cloud products: algorithms and examples from Terra, IEEE T. Geosci. Remote, 41, 459-473, doi:10.1109/TGRS.2002.808301, 2003.

Shamir, E. and Georgakakos, K. P.: MODIS Land Surface Temperature as an index of surface air temperature for operational snowpack estimation, Remote Sens. Environ., 152, 83-98, 2014.

Shen, S. H. and Leptoukh, G. G.: Estimation of surface air temperature over central and eastern Eurasia from MODIS land surface temperature, Environ. Res. Lett., 6, 045206, doi:10.1088/17489326/6/4/045206, 2011.

Vancutsem, C., Ceccato, P., Dinku, T., and Connor, S. J.: Evaluation of MODIS land surface temperature data to estimate air temperature in different ecosystems over Africa, Remote Sens. Environ., 114, 449-465, doi:10.1016/j.rse.2009.10.002, 2010.
Van Den Broeke, M., Reijmer, C., Van As, D., and Boot, W. Daily cycle of the surface energy balance in Antarctica and the influence of clouds, Int. J. Climatol., 26, 1587-1605, doi:10.1002/joc.1323, 2006.

Wan, Z.: New refinements and validation of the MODIS LandSurface Temperature/Emissivity products, Remote Sens. Environ., 112, 59-74, doi:10.1016/j.rse.2006.06.026, 2008.

Wan, Z. and Dozier, J.: A generalized split-window algorithm for retrieving land-surface temperature from space, IEEE T. Geosci. Remote, 34, 892-905, 1996.

Wan, Z., Zhang, Y., Zhang, Q., and Li, Z.-L.: Validation of the landsurface temperature products retrieved from Terra Moderate Resolution Imaging Spectroradiometer data, Remote Sens. Environ., 83, 163-180, 2002.

Wang, W., Liang, S., and Meyers, T.: Validating MODIS land surface temperature products using long-term nighttime ground measurements, Remote Sens. Environ., 112, 623-635, 2008.

Westermann, S., Langer, M., and Boike, J.: Spatial and temporal variations of summer surface temperatures of high-arctic tundra on Svalbard - Implications for MODIS LST based permafrost monitoring, Remote Sens. Environ., 115, 908-922, doi:10.1016/j.rse.2010.11.018, 2011.

Westermann, S., Langer, M., and Boike, J.: Systematic bias of average winter-time land surface temperatures inferred from MODIS at a site on Svalbard, Norway, Remote Sens. Environ., 118, 162167, 2012.

Williamson, S. N., Hik, D. S., Gamon, J. A., Kavanaugh, J. L., and Koh, S.: Evaluating cloud contamination in clear-sky MODIS Terra daytime land surface temperatures using ground-based meteorology station observations, J. Climate, 26, 1551-1560, 2013.

Wu, Y., Wang, N., He, J., and Jiang, X.: Estimating mountain glacier surface temperatures from Landsat-ETM+ thermal infrared data: A case study of Qiyi glacier, China, Remote Sens. Environ., 163, 286-295, 2015.

$\mathrm{Xu}, \mathrm{Y} ., \quad$ Knudby, A., and Ho, H. C.: Estimating daily maximum air temperature from MODIS in British Columbia, Canada, Int. J. Remote Sens., 35, 8108-8121, doi:10.1080/01431161.2014.978957, 2014.

Yang, W., Guo, X., Yao, T., Yang, K., Zhao, L., Li, S., and Zhu, M.: Summertime surface energy budget and ablation modeling in the ablation zone of a maritime Tibetan glacier, J. Geophys. Res.-Atmos., 116, D14116, doi:10.1029/2010JD015183, 2011.

Yu, J., Zhang, G., Yao, T., Xie, H., Zhang, H., Ke, C., and Yao, R.: Developing Daily Cloud-Free Snow Composite Products From MODIS Terra\&\#x2013;Aqua and IMS for the Tibetan Plateau, IEEE T. Geosci. Remote, 54, 2171-2180, doi:10.1109/TGRS.2015.2496950, 2016.

Yu, W. and Ma, M.: Validation of the MODIS Land Surface Temperature Products - A Case Study of the Heihe River Basin, Remote Sens. Technol. Appl., 26, 705-712, 2011.

Zeng, L., Wardlow, B. D., Tadesse, T., Shan, J., Hayes, M. J., Li, D., and Xiang, D.: Estimation of daily air temperature based on MODIS land surface temperature products over the corn belt in the US, Remote Sens., 7, 951-970, 2015.

Zhang, H., Zhang, F., Ye, M., Che, T., and Zhang, G.: Estimating daily air temperatures over the Tibetan Plateau by dynamically integrating MODIS LST data, J. Geophys. Res.-Atmos., 121, 11425-11441, doi:10.1002/2016JD025154, 2016. 
Zhang, W., Huang, Y., Yu, Y. Q., and Sun, W. J.: Empirical models for estimating daily maximum, minimum and mean air temperatures with MODIS land surface temperatures, Int. J. Remote Sens., 32, 9415-9440, doi:10.1080/01431161.2011.560622, 2011.
Zhu, W., Lű, A., and Jia, S.: Estimation of daily maximum and minimum air temperature using MODIS land surface temperature products, Remote Sens. Environ., 130, 62-73, doi:10.1016/j.rse.2012.10.034, 2013. 